\title{
МЕТОДЫ КЛАССИФИКАЦИИ И УПРАВЛЕНИЯ ЗАТРАТАМИ НЕФТЕГАЗОДОБЫВАЮЩЕГО МЕСТОРОЖДЕНИЯ
}

\author{
(C) 2019 Дьяченко Ольга Игоревна \\ магистр \\ DECENT, Словакия, Братислава \\ E-mail: Olga.Diachenko12@gmail.com
}

В статье представлен обзор существующих подходов к классификации издержек; проведен анализ стандартных методов управления затратами, и выявлены их недостатки. Представлена методика детализации затрат в соответствии с производственным циклом добычи нефти. Введено понятие «условно-прямых» затрат на производственную единицу и инфраструктурный объект; определены принципы расчета «условно-прямых» затрат; обозначена практическая значимость методики.

Ключевые слова: Издержки нефтегазодобывающих месторождений, детализированная оценка затрат, классификация издержек, производственный цикл добычи нефти, “условно-прямые затраты", затраты на эксплуатацию единиц производства, затраты на эксплуатацию нефтяной скважины, затраты на эксплуатацию объектов инфраструктуры

\section{Особенности классификации издержек в производстве нефти и газа}

В теории и практике существует ряд подходов к классификации издержек производства, структура которых зависит от продолжительности анализируемого периода. По принципу функциональности выделяют производственные издержки, издержки обращения, распределения, финансирования и управления. Издержки делят на рассчитанные в фактических («бухгалтерские издержки») и более выгодных, альтернативных («экономические издержки»), ценах.

Среди существующего многообразия классификации выделяют также смешанные, альтернативные, необратимые, вмененные и другие виды затрат [1;2].

Структура и состав затрат в нефтегазодобывающей промышленности определяется рядом особенностей отрасли [3; 4]:

- Добыча одновременно двух продуктов - нефти и газа, и, как следствие необходимость распределения затрат между ними.

- Производственный процесс добычи является четко определенным, последовательным и включает следующие этапы, по которым распределяются производственные издержки: извлечение нефти, ее технологическая подготовка, включающая отделение попутного нефтяного газа и транспортировка. Перечисленные стадии связаны с рядом процессов, выделяемых в самостоятельные калькуляционные статьи затрат.
- Значительную долю затрат в нефтедобыче составляют затраты на электроэнергию. При этом на себестоимость производства нефти влияет также способ добычи, который может быть фонтанным, щадящим, основанным на компрессорном методе, глубинно-насосным или газлифтным, и выбор которого существенно влияет на энергетические издержки. Так, фонтанный способ является самым дешевым, а глубинно-насосный и газлифтный наиболее высоко затратными методами.

- С целью постоянного поддержания пластового давления, в скважину закачиваются химические реагенты, вода, газ и производятся другие мероприятия, что увеличивает конечную себестоимость добычи.

- Удаленность предмета труда - нефти и газа - а также подземной части оборудования скважины от пункта наблюдения - аппаратов управления, что влияет на характер формирования издержек добычи нефти и газа. В частности, появляются дополнительные расходы на покупку и обслуживание инфраструктуры по наблюдению за процессом производства, а также затраты, связанные со строительством и обслуживанием инфраструктуры - дорог, высоковольтных линий и прочее на месте производства.

- Выделение затрат на обслуживание самой скважины в отдельную калькуляционную статью в связи с высокой значимостью скважины как вида основных средств.

- Отсутствие в себестоимости продукции 
сырьевых издержек производства, а именно издержек на сырье и материалы, необходимых для непосредственной добычей нефти.

- Отсутствие полуфабрикатов и незавершенного производства, благодаря чему все издержки списываются полностью на конечную себестоимость продукции без необходимости распределения расходов между готовой продукцией и незавершенным производством.

- Производственный процесс характеризуется многоэтапностью и комплексностью со сложной и масштабной структурой вспомогательного производства.

- Ухудшение геолого-технологических условий эксплуатации, связанных со снижением дебита и, как результат, ростом издержек.

Колядов и другие [5] при исследовании издержек компаний нефтяной и газовой промышленности выделяют их следующие свойства:

- образование издержек сопряжено с потреблением товаров, услуг (сырья, материалов, энергии, труда);

- потребление товаров/услуг должно характеризоваться стоимостной оценкой;

- результатом потребления товара/услуги является производство продукции;

Понятия издержек, используемых в нефтегазодобывающей промышленности объединены в таблице 1.

В рамках данного исследования использованы классификации издержек в разрезе прямых и косвенных, а также постоянных, переменных, валовых и эксплуатационных, которые подробнее рассмотрены в таблице 2. Описанные в таблице классификации издержек стали предметом изучения многих исследователей современной экономической теории. Рассмотрим результаты некоторых исследований:

Некоторые экономисты подразделяют постоянные затраты на две составляющие [8]:

- затраты, характеризуемые мощностью производства;

Таблица 1. Наиболее широко используемые виды издержек в нефтегазодобывающей промышленности

\begin{tabular}{|l|l|}
\hline Продуктивные издержки & $\begin{array}{l}\text { Издержки на создание ценности (к ним относятся издержки, связанные } \\
\text { с производством товара, а также выводом его на рынок и сбытом) }\end{array}$ \\
\hline Вспомогательные издержки & $\begin{array}{l}\text { Затраты, не создающие ценности, но неизбежные в процессе производ- } \\
\text { ства (к ним относятся ведение бухгалтерского учета, работа с персона- } \\
\text { лом и прочие издержки, присущие функции поддержки бизнеса) }\end{array}$ \\
\hline Издержки на контроль & $\begin{array}{l}\text { это затраты на предотвращение негативных результатов (в том числе } \\
\text { мониторинг деятельности поставщиков и подрядчиков) }\end{array}$ \\
\hline Непроизводительные издержки & Затраты, связанные бездействием (например, простоями оборудования) \\
\hline
\end{tabular}

\section{Таблица 2. Классификации издержек}

\begin{tabular}{|c|c|}
\hline \multicolumn{2}{|r|}{ Валовые и эксплуатационные издержки } \\
\hline Валовые затраты & совокупные затраты на различных уровнях производства [6] \\
\hline Эксплуатационные затраты & $\begin{array}{l}\text { «..расходы, связанные с эксплуатацией машин, оборудования, транспортных } \\
\text { средств и т.д.» [7] }\end{array}$ \\
\hline \multicolumn{2}{|r|}{ Прямые и косвенные издержки } \\
\hline Прямые издержки & $\begin{array}{l}\text { ресурсы, непосредственно затраченные на производство единицы продук- } \\
\text { ции (объем материалов, энергии, времени сотрудников и другие расходы). }\end{array}$ \\
\hline Косвенные издержки & $\begin{array}{l}\text { издержки, которые не связаны с производством напрямую, но относятся к } \\
\text { деятельности компании в целом (например, использование одного станка } \\
\text { для производства различных видов продукции) [6]. }\end{array}$ \\
\hline \multicolumn{2}{|r|}{ Постоянные и переменные издержки } \\
\hline $\begin{array}{l}\text { Переменные издержки } \\
\text { (по англ. variable costs, далее } \\
\text { по тексту «VC») }\end{array}$ & $\begin{array}{l}\text { стоимость ресурсов, необходимых для производства единицы продукции, } \\
\text { величина которых непосредственно зависит от объема и структуры произ- } \\
\text { водства. Различают пропорциональные и непропорциональные выпуску } \\
\text { продукции переменные издержки. }\end{array}$ \\
\hline $\begin{array}{l}\text { Постоянные издержки } \\
\text { (по англ. fixed costs, «FC») }\end{array}$ & $\begin{array}{l}\text { фиксированные расходы, не зависящие от степени загрузки производствен- } \\
\text { ных мощностей и объема производства. К ним относят арендную плату, } \\
\text { фиксированную заработную плату работников, ремонтные и эксплуатаци- } \\
\text { онные работы. Удельный вес постоянных издержек характеризует степень } \\
\text { гибкости предприятия. }\end{array}$ \\
\hline
\end{tabular}


- затраты управления, отражающие политику администрирования компании.

Подобный подход используется в практике нефтегазодобывающих компаний, когда часть постоянных расходов относится на обслуживание и эксплуатацию оборудования, а часть на административно-хозяйственную деятельность.

Важно отметить, что отнесение затрат к постоянным и переменным условно. Так, Воронцовский (1999) при оценке эффективности инвестиционного проекта подразделял затраты только на «условно-переменные» и «условно-постоянные». Альтернативной точки зрения придерживались Ковалев и Волкова, которые подчеркивали, что при разработке алгоритмов аналитической оценке часто принимаю деление затрат на постоянные, переменные и условнопеременные, которые могут принимать форму постоянных в зависимости от уровня производства.

Разделение издержек на постоянные и переменные является одним из ключевых атрибутов качественной оценки эффективности. По мнению Коласса (1997), упрощенная схема деления издержек на переменные и постоянные может привести к искажению результатов оценки эффективности производства компании [9].

Стоянова (2006) [10] изучала влияние роста объема производства на изменение постоянных и переменных затрат. Зависимость динамики постоянных и переменных затрат от объемов производства нефти зафиксировано в таблице 3. Как видно из таблицы, совокупные переменные издержки изменяются прямо-пропорционально объему производства при неизменном значении удельных переменных затрат на единицу продукции. В то же время сумма постоянных издержек остается неизменной при изменении объема производства, однако, удельная норма постоянных затрат на единицу продукции обратно пропорциональна изменению объема производства.

Деление затрат на постоянные и переменные позволяет выявить влияние объема произ- водства на величину конечной прибыли от реализации продукции, работ или услуг.

Рассматривая валовые издержки, математически формула имеет следующий вид:

$$
T C=V C+F C
$$

где ТC - общие издержки, VC - переменные затраты на единицу продукции, Q - объем производства, FC - постоянные издержки.

$$
V C=V C^{\prime} Q
$$

где VC' - переменные затраты на единицу продукции, Q - объем производства.

Методы классификации, а также отраслевые особенности определяют подходы к управлению издержками нефтегазодобывающих месторождений.

Особенности управления издержками нефтегазодобывающих компаний

Управление издержками - это инструмент достижения компанией максимально эффективного результата. Предмет управления издержками на предприятиях нефтегазодобывающей промышленности есть все существующие затраты компании. При этом основными особенностями издержек являются:

- динамика - непрерывное изменение издержек в процессе деятельности компании, что связано, например, с меняющимися тарифами на топливо и электроэнергию, ценами на сырье и материалы, нормами расхода ресурсов и другие факторы;

- разнообразие - издержки компании носят дифференцированный характер, связанный с производственной, общехозяйственной, коммерческой и иной деятельностью, что требует применения различных методов управления издержками, градация которых основывается на существующей классификации затрат, позволяющей оценить степень влияния различных расходов на конечную экономическую эффективность деятельности компании;

Таблица 3. Зависимость изменения переменных и постоянных издержек от тренда объема производства

\begin{tabular}{|c|c|c|c|c|}
\hline \multirow{2}{*}{$\begin{array}{c}\text { Объем производ- } \\
\text { ства и реализации } \\
\text { продукции }\end{array}$} & \multicolumn{2}{|c|}{ Переменные издержки } & \multicolumn{2}{|c|}{ Постоянные издержки } \\
\cline { 2 - 5 } & Суммарные & $\begin{array}{c}\text { На единицу } \\
\text { продукции }\end{array}$ & Суммарные & $\begin{array}{c}\text { На единицу } \\
\text { продукции }\end{array}$ \\
\hline Повышается & Растут & Не изменяются & Не изменяются & Падают \\
\hline Снижается & Падают & Не изменяются & Не изменяются & Растут \\
\hline
\end{tabular}

Источник: исследования автора 
- сложность учета и оценки затрат, обусловленная отсутствием абсолютно точных и достоверных методик измерения и дальнейшего учета;

- противоречивость влияния на конечную экономическую эффективность деятельности компании. Например, повышение эффективности достигается в результате снижения издержек на производство за счет роста инвестиций в новые технологии.

Одним из важнейших показателей является показатель затрат на единицу товарной продукции, который отражает эффективность управления издержками компаний. При этом повышение рентабельности производства продукции оказывает прямое влияние на снижение конечной себестоимости [11].

В основе управления затратами нефтегазодобывающей отрасли лежит бухгалтерский и управленческий учет. При этом основной целью управленческого учета является достижение запланированных показателей производственно-хозяйственной деятельности фирмы.

Системы управления издержками нефтегазодобывающих компаний

Традиционно функцию управления издержками в компании выполняет система контроллинга и управленческого учета. Наибольший интерес с точки зрения управления представляет контроллинг.

Контроллинг - это интегрированная система планирования и контроля прибыльности компании, осуществляемых на основании информационного обеспечения. Целью контроллинга является достижение стратегической цели компании - максимальной прибыли - за счет контроля издержек и рентабельности производства. Именно процесс контроллинга связывают с понятием ликвидации «узких мест», определяемых в процессе контроллингового анализа.

Выделяют стратегический и оперативный контроллинг. Стратегический контроллинг фокусируется на стратегических долгосрочных целях компании, в то время как оперативных контроллинг решает текущие производственные краткосрочные и среднесрочные задачи [12].

Одним из наиболее важных моментов в контроллинге является учет затрат по местам их формирования, или, иными словами, по центрам возникновения затрат [13].

Модель оперативного контроллинга решает следующие задачи:

- установление центров затрат и ответ- ственности в разрезе производственных и функциональных подразделений.

- формирование принципов оперативного планирования и управления деятельностью компании в соответствии с установленными центрами затрат и ответственности.

Анализируя теорию контроллинга с точки зрения достижения максимизации эффективности работы нефтегазодобывающей компании за счет своевременного выявления точной причины снижения эффективности, можно выделить ее недостатки: относительно низкая эффективность сравнения плановых и фактических показателей и выработке рекомендаций на основании разработанных норм затрат [14]; плановые показатели рассчитываются на основании нормирования затрат или на основании фактических результатов, полученных за предыдущие периоды; нормирование затрат является наиболее широко распространенным способом планирования в нефтегазодобывающей отрасли; анализ проводится не детальнее, чем в разрезе производственных цехов; анализ проводится не чаще, чем раз в месяц. кроме того.

Эти недостатки выявляют необходимость внедрения новых подходов, основанных на комплексном анализе экономической эффективности эксплуатации месторождений. Такие подходы должны предусматривать проведение анализа в разрезе минимальных производственных единиц на ежесуточной основе. Сравнение существующих характеристик управления издержками контроллинга и необходимых характеристик новых подходов управления издержками нефтегазодобывающих компаний, приведено в таблице 4.

Как видно из приведенного исследования, существующие проблемы обуславливают необходимость разработки и внедрения методики детализированной оценки текущих затрат в разрезе всех существующих центров формирования затрат: производственных единиц и инфраструктурных объектов.

Методика детализированной оценки издержек

Предложенная методика является продолжением методики, описанной автором в предыдущих работах [15]. В основе методики лежит производственный цикл добычи нефти, позволяющий детализировать издержки по центрам ответственности. Рассмотрим классический подход к определению технологической 
Таблица 4. Сравнение существующих характеристик управления издержками контроллинга и необходимых характеристик управления издержками

\begin{tabular}{|l|l|l|}
\hline \multicolumn{1}{|c|}{ Критерий сравнения } & $\begin{array}{l}\text { Существующие характеристики } \\
\text { управления издержками кон- } \\
\text { троллина }\end{array}$ & $\begin{array}{c}\text { Необходимые характеристики } \\
\text { методики управления издерж- } \\
\text { ками }\end{array}$ \\
\hline Цель & \multicolumn{1}{|c|}{ Контроль издержек и рентабельности производства } \\
\hline $\begin{array}{l}\text { Задача } \\
\text { решения }\end{array}$ & Выявление и ликвидация «узих мест» производственного процесса \\
\hline Инструмент & $\begin{array}{l}\text { Коллективное принятие решения, выработанное на основании группо- } \\
\text { вой работы }\end{array}$ \\
\hline Периодичность & $\begin{array}{l}\text { Сравнение плановых и фактиче- } \\
\text { ских показателей. Использование } \\
\text { нормирования при расчете плано- } \\
\text { вых показателей }\end{array}$ & $\begin{array}{l}\text { Определение экономической } \\
\text { эфективности за счет анализа } \\
\text { фактического текущего денежного } \\
\text { потока }\end{array}$ \\
\hline $\begin{array}{l}\text { Минимальная анализируемая } \\
\text { единица }\end{array}$ & Ежемесячно & Ежесуточно в режиме оn-line \\
\hline
\end{tabular}

Источник: исследования автора

системы добычи [16; 17; 18], который принят в большинстве нефтегазодобывающих компаний страны и взят за основу в данном исследовании. Согласно последовательности производственного цикла (Рис. 1), добытая нефть с примесями поступает из недр земли по пробуренным скважинам и перекачивается на автоматизированные групповые замерные установки (АГЗУ), на которых осуществляется учет валового объема нефти, поступившей от каждой скважины. Затем нефть перекачивается по внутрипромысловым трубопроводам на дожимные насосные станции (ДНС), на которых она подвергается частичной дегазации и обезвоживанию, после чего перекачивается на центральный пункт сбора (ЦПС). Отделенная и подготовленная вода поступает на кустовые насосные станции (КНС) и далее под давлением закачивается в пласты. Единая технологическая система сбора и подготовки нефти и попутного газа на месторождениях заканчивается на установке комплексной подготовки нефти (УКПН), где производится комплекс технологических мероприятий по подготовке нефти.

Таким образом, предложенные принципы детализации по этапам производственного цикла добычи лежат в основе определения эффективности и отнесения затрат, которые группируются следующим образом:

1. Определение затрат на скважины

2. Группировка затрат по кусту

3. Группировка затрат по дожимным насосным станциям (ДНС) и установка предварительного сброса воды (УПСВ).

4. Группировка затрат по кустовым насосным станциям (КНС).
5. Группировка затрат по центральному пункту сбора (ЦПС)

6. Группировка затрат по дорогам

7. Группировка затрат по трубопроводам

8. Группировка затрат по высоковольтным линиям (ВЛ)

9. Группировка затрат по месторождению

10. Группировка затрат в целом по Компании

В связи с отсутствием понятийного аппарата для определения затрат производственных единиц и инфраструктурных объектов в существующих методологических и практических подходах, введем следующие понятия:

Затраты на эксплуатацию единиц производства - расходы на содержание и обслуживание скважин, кустов и месторождений. К этим затратам будем относить:

- Затраты на содержание и эксплуатацию скважины;

- Затраты на содержание и эксплуатацию куста;

- Затраты на содержание и эксплуатацию месторождения.

Затраты на эксплуатацию объектов инфраструктуры - это расходы на содержание и обслуживание технологических объектов, обеспечивающих прохождение нефти по этапам производственного цикла сбора, технологической подготовки и транспортировки. К затратам на эксплуатацию инфраструктурных объектов будем относить:

- Затраты на содержание и эксплуатацию труб, ВЛ и дорог.

- Затраты на содержание и эксплуатацию 


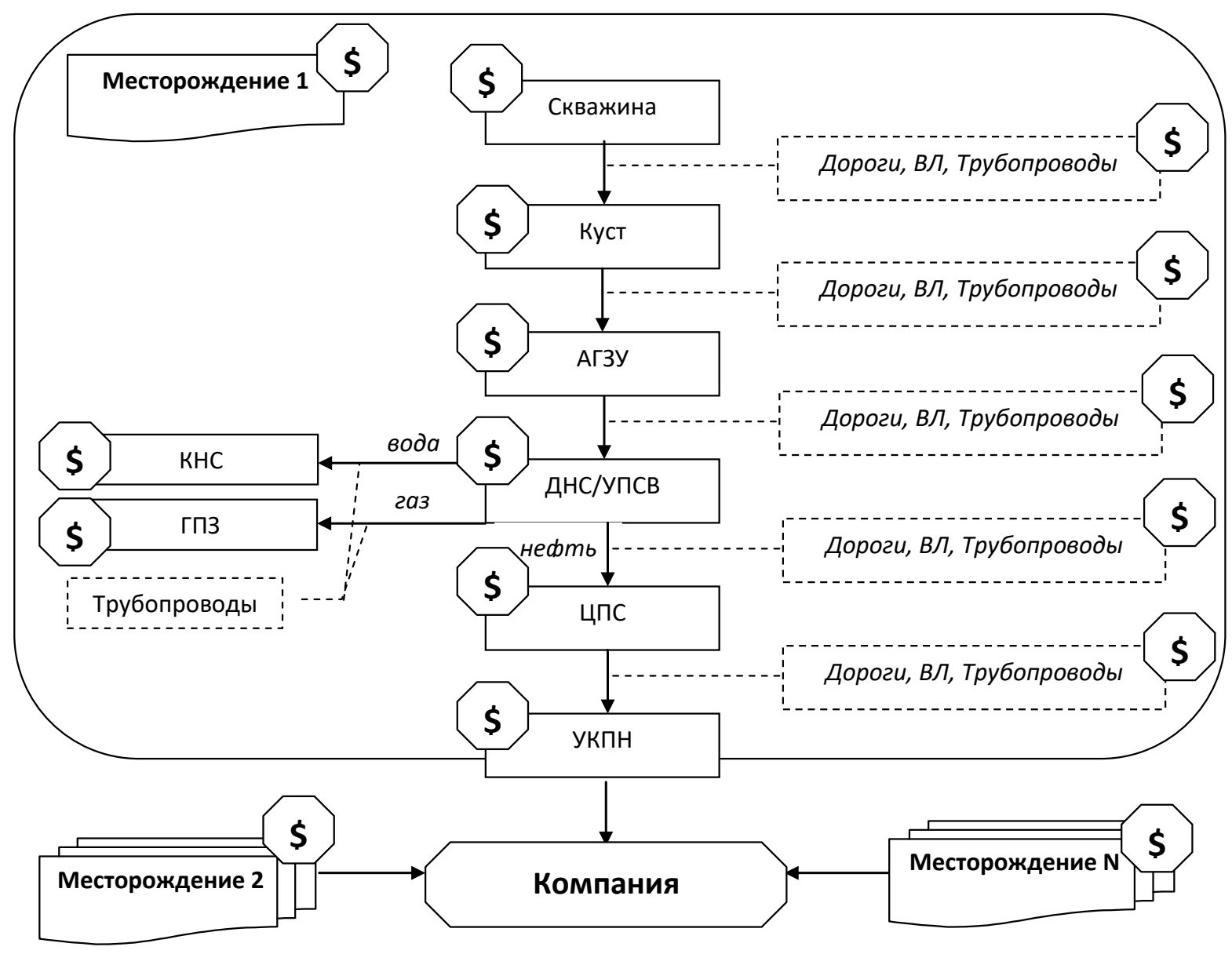

Комментарий: \$ - условное обозначение затрат

Puc. 1. Предлагаемая схема определения расходов нефтегазодобывающей компании

\section{ДНС/УПСВ}

- Затраты на содержание и эксплуатацию ЦПС

- Затраты на содержание и эксплуатацию $\mathrm{KHC}$

Определение понятия «условно-прямых затрат» как элемента управления эффективностью [19]

Как уже было отмечено выше, эксплуатационные издержки формируются из суммы переменных и постоянных расходов.

Переменные затраты - это затраты, зависящие от объема добываемой нефти.

Постоянные затраты - это затраты на содержание и обслуживание единицы производства или инфраструктурного объекта, не зависящие от объема добываемой продукции.

Проведенное исследование показало, что для получения более достоверной оценки единиц производства/инфраструктурных объектов необходимо анализировать только переменные и постоянные затраты на скважину, которые в случае их остановки принесут предприятию прямую экономию денежных средств. Для них мы вводим понятие «условно-прямые затраты на единицу производства/инфраструктурный объект».

«Условно-прямые затраты на единицу производства/ инфраструктурный объект» - это такие расходуемые для производства продукции ресурсы, которые в случае оптимизации процесса добычи могут обеспечить прямую экономию денежных средств.

К таким затратам относятся, в первую очередь, расходы по электроэнергии на механизированную добычу, содержание и обслуживание оборудования, текущий ремонт и т.п. [20]

При определении «условно-прямых затрат» учитывались переменные расходы по следующим процессам:

- расходы на энергию по извлечению нефти; 
- расходы по искусственному воздействию на пласт;

- расходы по сбору и транспортировке нефти;

- расходы по технологической подготовке нефти;

, а также затраты постоянные по статье «расходы на содержание и эксплуатацию оборудования» калькуляции [21].

Условно-прямые затраты на единицы производства включают:

- условно-прямые затраты на скважину

- условно-прямые затраты на куст

- условно-прямые затраты на месторождение

В сумму условно-прямых затрат на скважину включаются как переменные, так и постоянные затраты по ней:

$$
\sum \mathbf{3}_{\mathrm{CKB}}=\mathrm{VC}_{\mathrm{CKB}}+\mathrm{FC}_{\mathrm{CKB}}
$$

где $3_{\text {скв }}-$ совокупные условно-прямые затраты на скважину, $\mathrm{VC}_{\text {скв }}$ - переменные условно-прямые затраты на скважину, $\mathrm{FC}_{\text {скв }}-$ постоянные условно-прямые затраты на скважину.

Переменная часть (VC) условно-прямых затрат включает затраты на добычу и подготовку нефти, перекачу жидкости, закачку воды в пласт и рассчитывается по следующей формуле:

$$
\mathbf{V C}=\text { Знефть }+ \text { Зжидкость }+ \text { Ззакачка (4) }
$$

, где Знефть - затраты на добычу и подготовку нефти; Зжидкость - затраты на перекачку жидкости; Ззакачка - затраты на закачку воды в систему поддержания пластового давления (ППД).

Для расчета переменной части условно-прямых затрат используются исходные производственные показатели работы, отраженные в Таблице 5.

Постоянные затраты (FC) - это затраты на суточное обслуживание оборудования, или за- траты за сутки проката оборудования, в соответствие с договором аренды. Затраты на обслуживание зависят от способа эксплуатации, который может быть фонтанным (ФОН), штангово-глубинным (ШГН) или электроцентробежным (ЭЦН). Обслуживание ЭЦН является самым затратным методом по причине высоких затрат на электроэнергию для эксплуатации насоса, тогда как фонтанный способ, требующий минимального оборудования, характеризуется наименьшими постоянными расходами на обслуживание.

Условно-прямые затраты на куст будем определять как сумму между затратами по всем скважинам куста и постоянными затратами на обслуживание куста.

$$
\sum \mathbf{3}_{\text {куст }}=\sum \mathbf{3}_{\text {скв }}+\mathbf{F C}_{\mathrm{kуст}}
$$

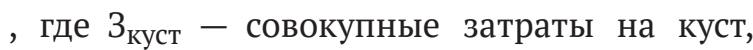
$\sum 3_{\text {скв }}$ - суммарные затраты по всем скважинам куста, $\mathrm{FC}_{\text {куст }}$ постоянные затраты на куст (затраты на основную и дополнительную заработную плату работников, содержание и обслуживание основных фондов куста).

При отключении одной или нескольких скважин куста, сумма постоянных затрат на его содержание и обслуживание останется прежней, даже в случае необходимости содержания только одной скважины. Поэтому с точки зрения экономики важно понимать, какие скважины являются наиболее затратными, с целью выявления возможности дальнейшей оптимизации.

Инфраструктурные объекты, также как и кусты, характеризуются только постоянной составляющей затрат на содержание и обслуживание, в связи с тем, что все переменные расходы, зависящие от объема добычи, относятся непосредственно на скважины.

Группировка по инфраструктурным объектам (ЦПС, КНС, ДНС и т.д.) предполагает отнесение к этим объектам кустов, с которых нефть

\begin{tabular}{|c|c|}
\hline $\begin{array}{c}\text { Исходные производственные показатели } \\
\text { для расчета затрат }\end{array}$ & Единица измерения \\
\hline Суточный дебит нефти, $q_{н}$ & Тонн в сутки (тн./сут) \\
\hline Суточный дебит жидкости, $q_{ж}$ & Кубических метров в сутки (м³/сут) \\
\hline Процентт обводненности, \% & Проценты (\%) \\
\hline Плотность нефти, & мПа* * \\
\hline
\end{tabular}
поступает на данные пункты и рассчитывается

Таблица 5. Исходные производственные показатели для определения условно-прямых затрат на скважину 
следующим образом:

$$
\mathbf{3}(\text { иоб })=\sum_{\mathbf{1}}^{\mathrm{n}} \text { Зкуст }+\mathrm{FC}_{\text {иоб }} .
$$

где 3(ИОб) - затраты на инфраструктурный объект, $\sum_{1}^{n}$ Зкуст - сумма затрат на кусты, с которых нефть поступает на инфраструктурный объект, $\mathrm{FC}_{\text {Иоб }}$ - постоянные затраты на содержание и обслуживание куста.

Важным моментом является подход к оценке затрат на автодороги, трубопроводы и ВЛ, которые расположены в территориальной близости каждого куста и инфраструктурного объекта. Предлагаемая методика предполагает отнесение затрат на обслуживание дорог, ВЛ и трубопроводов на кусты и инфраструктурные объекты, находящихся в непосредственной близости.

Последним этапом является определение затрат на содержание и эксплуатацию всего месторождения, равная сумме затрат кустов, инфраструктурных объектов и постоянных расходов на эксплуатацию месторождения [19]. Таким образом, предложенный подход позволяет:
- детализировать суммарные затраты месторождения по всем производственным единицам и инфраструктурным объектам,

- управлять затратами с точки зрения понимания возможности их оптимизации в рамках одной скважины и месторождения в целом.

Выводы

- в исследовании освещены существующие подходы к классификации и управлению издержками, применяемые для нефтегазодобывающих месторождений, проанализированы их основные недостатки

- обоснована необходимость расширения понятийного аппарата и внедрения термина «условно-прямых затрат» на производственную единицу или инфраструктурный объект как основной элемент управления затратами

- представлена методика детализации затрат в разрезе производственных единиц и инфраструктурных объектов, соответствующая производственному циклу добычи нефти

- представленные принципы нашли практическое применение в нефтяных компаниях РФ.

\section{Библиографический список}

1. Управленческий учет: Учеб. пособие / Под ред. Шеремета А.Д.- 2-е изд., испр.- М.: ФБК-ПРЕСС, 2001.C.32-36.

2. Баканов М.И., Мельник М.В., Шеремет А.Д. Теория экономического анализа: Учебник. / Под ред. Баканова М.И. - 5-е изд., перераб. и доп. - М.: Финансы и статистика, 2005. - 359 с.

3. Новоселова T.Н. Особенности формирования затрат на предприятиях нефтедобывающей промышленности. Финансовый менеджмент. 2007, № 7, С. 19-27

4. Андреев А.Ф., Зубарева В.Д., Саркисов А.С. Оценка эффективности и рисков инновационных проектов нефтегазовой отрасли: Учебное пособие.- М.: МАКС Пресс, 2007.-С. 18-22

5. Колядов Л.В., Матвеев Ф.Р., Епифанова Н.П., Отвагина ІІ.Н. Затраты и результаты: Учеб. пособие.- М.: ФГУП Изд-во «Нефть и газ» РГУ нефти и газа им. И.М. Губкина. 2005. - С. 8-9

6. Румянцева Е.Е. Новая экономическая энциклопедия. 3-е изд.- М.: ИНФРА-М, 2008.-VI, с.175.

7. Популярная экономическая энциклопедия/ Гл. ред. Некипелов Ф.Д.; Ред. кол.: Автономов В.С., Богомолов О.Т., Глинкина С.П. и др.- М.: Большая Российская энциклопедия, 2001.- с. 90.

8. Чумаченко Н.Г. Учет и анализ в промышленном производстве США.- М.: Финансы, 1971.

9. Коласс Б. Управление финансовой деятельностью предприятия. Проблемы, концепции и методы: Учебное пособие / Пер. с франц. под. ред. проф. Я.В. Соколова,-М.: Финансы, ЮНИТИ, 1997.

10. Финансовый менеджмент: теория и практика / Под. ред. Стояновой Е.С.-6-е изд.- М.: Изд-во «Перспектива», 2006.- с. 185.

11. Демченков В.С., Милета В.И. Системный анализ деятельности предприятий: - М.: Финансы и статистика, 1990 - С. $124-134$.

12. Фольмут Х.Й. Инструменты контроллинга от А до Я. / Пер. с немец.: М.: Финансы и статистика, 1997.- 800 c.

13. Дейли А., Штайгматер Б. Контроллер и контроллинг. М.: Финансовая газета, 1997, № 14.- С.10-13-15; № $15 .-$ c. $19-22$.

14. Дайле А. Практика контроллинга.- М.: Финансы и статистика, 2001, С. 242-246. 
15. Дьяченко О.И. Методика детализированной оценки операционной эффективности нефтегазодобывающей компании /Дьяченко О.И. // Экономи-ка и управление: Сборник научных трудов. / Под редакцией д-ра экон. наук, проф. А.Е. Карлика.-СПб.: Изд-во: СПбГЭУ, 2016 - С.113-125. - 0,6 п.л.

16. Гиматудинов Ш.К. (ред.) Справочное руководство по проектированию разработки и эксплуатации нефтяных месторождений. Под общ. ред. Ш.К. Гиматудинова / Р.С. Андриасов, И.Т. Мищенко, А.И. Петров и др. М.: Недра, 1983.-45c.

17. Гиматудинов Ш.К., Дунюшкин И.И, Зайцев В.М. и др.Разработка и эксплуатация нефтяных, газовых и газоконденсатных месторождений: Учеб. для вузов/ М.: Недра, 1988. - 302с.

18. Сулейманов Р.С., Хафизов А.Р., Шайдаков В.В., Чеботарев В.В. и др. Сбор, подготовка и хранение нефти и газа. Технологии и оборудование.- Уфа: Нефтегазовое дело, 2007.-450с.

19. Дьяченко О.И. Совершенствование аспектов экономического анализа при планировании и мониторинге эксплуатации месторождений нефтегазодобывающих организаций /Дьяченко О.И. // Экономический анализ. Теория и практика.- Финансы и Кредит. - 2012 - № 48(303) - С.-5-51.- 0,7 п.л.

20. Коробейников Н.Ю., Терегулова Г.Р. Особенности экономической оценки проведения геолого-технических мероприятий// Нефтяное хозяйство.-2001.- № 4, с.11-13

21. Положение о составе затрат по производству и реализации продукции (работ, услуг), включаемых в себестоимость продукции (работ, услуг) и о порядке формирования финансовых результатов, учитываемых при налогообложении прибыли. Утверждено постановлением Правительства Российской Федерации № 552 от 5 августа 1992 года, с изменениями и дополнениями 